\title{
EXPANSÃO DA EDUCAC̣ÃO SUPERIOR E FORMAC̣ÃO DE PROFESSORES NOS ESTADOS DO PARÁ E DO RIO GRANDE DO NORTE
}

\author{
Arlete Maria Monte de Camargo* \\ Universidade Federal do Pará, (UFPA), Belém - PA, Brasil \\ Alda Maria Duarte Araújo Castro** \\ Universidade Federal do Rio Grande do Norte, (UFRN), Natal - RN, Brasil
}

RESUMO: O artigo apresenta uma análise da expansão da educação superior em cursos de formação de professores em uma das possíveis organizações institucionais previstas pela Lei $\mathrm{n}^{\circ}$ 9.394/1996, as universidades. Procura comparar a realidade dos estados do Pará e do Rio Grande do Norte, por meio de dados estatísticos, no período compreendido entre 2003 e 2010, a partir de consulta à base de dados do Instituto Nacional de Estudos e Pesquisa Educacionais Anísio Teixeira (INEP). Os resultados evidenciam que ainda prevalece a oferta majoritária de cursos de licenciatura nas universidades, considerando-se o número total de matrículas e vagas ofertadas, apesar da ampliação desses quantitativos em faculdades, centros universitários e institutos federais. Isso indica que a tarefa de formação de professores vem sendo assumida por instituições que não têm tradição nessa área.

Palavras-chave: Educação superior. Expansão. Formação de professores. Organização acadêmica.

\section{EXPANSION OF HIGHER EDUCATION AND TEACHERS EDUCATION PROGRAMS IN THE STATES OF PARÁ AND RIO GRANDE DO NORTE}

ABSRACT: The article presents an analysis of the expansion of higher education in teachers' education provided, in Brazil, by one of the possible academic organizations established by Law n. 9.394/1996 - the universities. It tries to compare the reality of the states of Pará and Rio Grande do Norte, based on statistical data from the database of the Anisio Teixeira National Institute for Educational Studies and Research (INEP), in the period between 2003 and 2010. The results have shown that the majority offer of teachers education undergraduate programs still prevails in universities,

http://dx.doi.org/10.1590/0102-4698161856

"Doutora em Educação pela Universidade Federal de Minas Gerais (UFMG). Professora integrante do Grupo de Estudos e Pesquisas em Educação Superior - GEPES/UFPA. E-mail: < acamargo@ufpa.br > , $<$ iced@ufpa.br>.

"* Doutora em Educação pela Universidade Federal do Rio Grande do Norte (UFRN). Professora do Programa de Pós-Graduação em Educação da UFRN. E-mail: < aldacastro01@hotmail.com>. 
considering the total number of vacancies offered and enrollment, in spite of the growing expansion of such numbers in colleges, universitary centers and in the Federal institutes. This indicates that institutions that have no tradition in this area have assumed the task of teachers' education.

Keywords: High education. Expansion. Teachers' education. Academic organization.

\section{INTRODUÇÃO}

O artigo aqui apresentado é fruto de estágio pós-doutoral realizado na Universidade Federal do Rio Grande do Norte no ano de 2014. Teve como referência o projeto "Políticas da Expansão da Educação Superior no Brasil", em curso pela Rede Universitas/Br, que investiga as políticas de expansão da educação superior após a aprovação da Lei no 9.394/1996 (BRASIL, 1996) - Lei de Diretrizes e Bases da Educação Nacional (LDB).

Foi desenvolvido um estudo de caso que toma em consideração a realidade dos estados do Pará e do Rio Grande do Norte no que diz respeito à expansão da educação superior, à organização acadêmica e à formação de professores a partir de uma série histórica que abrange o período de 2003 a 2010. Neste artigo, foi feito um recorte, com vistas a entender esses fenômenos nas universidades, uma das modalidades de organização acadêmica previstas, em relação às quais já havia sido identificada uma redução dos índices de expansão, em geral, quando comparadas a outras formas de organização (RISTOFF; GIOLO, 2006).

A necessidade de criação de instituições universitárias, no Brasil, ganhou força na década de 1920, quando, segundo Fávero (2006), foi acentuada a discussão sobre a importância e o papel dessas instituições para a formação de professores. Essas preocupações irão se materializar nos anos de 1930, quando foram criadas a Universidade de São Paulo (USP) e Universidade do Distrito Federal (UDF), ambas consideradas referência sobre essa questão.

No que diz respeito à formação de professores na universidade, tanto a USP como a UDF incluíam, em sua constituição, unidades voltadas para este objetivo. Desde então, as universidades tiveram como uma das suas tarefas centrais a formação de professores para o chamado ensino secundário ${ }^{2}$, conforme afirmam Charlot e Silva (2010, p. 51):

No Brasil, observa-se o mesmo processo fundamental: o nascimento das faculdades contemporâneas foi estreitamente ligado à questão da formação dos professores do ensino secundário. Ela foi central no decreto de Francisco Campos de 1931, exigindo a licenciatura para lecionar no ensino secundário e promovendo a ideia de Faculdade de Educação, Ciências e Letras, no Movimento da Escola 
Nova das décadas de 1920 e 1930 e no Manifesto dos Pioneiros de 1932, na criação da Faculdade de Filosofia, Ciências e Letras da USP (1934), inspirada por Fernando de Azevedo, e da Universidade do Distrito federal (UDF, 1935), concebida por Anísio Teixeira.

Em estudo sobre a mudança do papel da universidade e seu impacto em países de baixa renda, Mccowan e Schendel (2015) destacam a subordinação das instituições universitárias ao modelo de desenvolvimento de organismos internacionais como o Banco Mundial - BM, como fator que contribui para reduzir a margem de manobra dessa instituição como autônoma, orientada pela justiça social e politicamente crítica. Para esses autores, na reconfiguração da universidade contemporânea, ganha força o entendimento de que as atividades desenvolvidas nas universidades "devem ter - e devem demonstrar através de indicadores quantitativos (de preferência) um impacto econômico e social positivo nas sociedades ao redor delas" (McCOWAN; SCHENDEL, 2015, p. 20).

Essa reconfiguração do papel da universidade se relaciona, entre outros aspectos, com a pressão crescente pela ampliação da formação de profissionais para o mercado de trabalho, pela participação de grupos sociais que sempre estiveram marginalizados na vida acadêmica, além da pressão sobre os orçamentos públicos e a alocação desses recursos, o que acaba por impactar igualmente a instituição universitária no contexto brasileiro.

Em relação à formação de professores em nível superior, objeto deste artigo, com a aprovação da LDB no 9.394/1996, essa formação passou a ser exigida para atuação na Educação Infantil e nas quatro primeiras séries do Ensino Fundamental, o que, até então, não era considerado obrigatório. Isso ficou explícito a partir do artigo 62 da referida lei.

Art. 62. A formação de docentes para atuar na educação básica far-se-á em nível superior, em curso de licenciatura, de graduação plena, em universidades e institutos superiores de educação, admitida, como formação mínima para o exercício do magistério na educação infantil e nas quatro primeiras séries do ensino fundamental, a oferecida em nível médio, na modalidade Normal. (BRASIL, 1996)

Essa exigência, em um primeiro momento, ocasionou uma acentuada procura por cursos de nível superior já que significativa parcela do corpo docente brasileiro não atendia a essa exigência. Segundo dados do ano de 1997 divulgados no Censo do Professor, foram identificadas 1.617.611 funções docentes nas escolas da Educação Básica (INEP, 1999). Dessas, 785.637 eram exercidas por 
professores que possuíam formação em nível superior obtida em cursos de licenciatura, sendo, ainda, registradas funções docentes exercidas por professores que possuíam apenas o $1^{\circ} \mathrm{Grau}$ (completo ou não), $2^{\circ}$ Grau completo, e formação em nível de $3^{\circ}$ Grau ou mais ${ }^{3}$.

Por exemplo, na Região Norte, das funções docentes identificadas naquele ano, 5,3\% eram exercidas por professores com formação em nível superior; na Região Nordeste, esse percentual atingia 10,5\% das funções, sendo a Região Sudeste a região brasileira com maior percentual desses professores com nível superior $40 \%$, o que evidenciava as assimetrias regionais e um percentual significativo de funções docentes exercidas por professores sem a devida certificação (INEP, 1999).

O aumento da demanda motivou a expansão dos cursos de licenciatura, sobretudo, com o incremento de políticas de ampla envergadura voltadas para a formação em serviço, com recursos oriundos, inicialmente, do Fundo de Manutenção e Desenvolvimento do Ensino Fundamental e de Valorização do Magistério ${ }^{4}$ (Fundef), o qual viria a ser, posteriormente, substituído pelo Fundo de Manutenção e Desenvolvimento da Educação Básica e de Valorização dos Profissionais da Educação (Fundeb). ${ }^{5}$

Sobre esse assunto, Gatti, Barreto e André (2011, p. 34) afirmam que a política de fundos trouxe inúmeras consequências à educação básica, entre essas que

[...] novas articulações fossem estabelecidas entre as administrações mantenedoras da educação básica e as instituições formadoras de professores. Vários governos dos estados e dos municípios passaram a trabalhar em parceria, mediante convênios com universidades federais, estaduais e, por vezes, algumas comunitárias dos respectivos estados, para o desenvolvimento de programas especiais de licenciatura voltados aos professores em exercício nas redes públicas que possuíam apenas formação em nível médio, conforme requeria a legislação anterior. Os programas eram semipresenciais e utilizavam recursos midiáticos diversos, uma vez que havia necessidade de certificar grande número de professores, gerando uma demanda de larga escala que os cursos regulares da educação superior, no seu formato clássico, não tinham condições de atender a curto ou médio prazo. Com o Fundeb, alargase o escopo desses programas.

Apesar da ampliação dos esforços com vistas ao aumento da qualificação docente por via do Fundef e Fundeb, verificou-se que, decorridos 10 anos após a aprovação da LDB, ainda persistia um percentual significativo de professores atuando sem a devida qualificação. No ano de 2007, foram registradas, na Educação Básica, 1.882.961 funções docentes; dessas, 1.160 .881 eram ocupadas por professores com diploma de nível superior obtido em cursos de 
licenciaturas (INEP, 2007), o que corresponde a 61,6\% de professores com esse nível de ensino, além de 38,4\% de funções docentes sem a qualificação prevista pela legislação.

Se, em um primeiro momento, houve uma acentuada procura pelos cursos de licenciatura, aos poucos essa situação vai sendo modificada, já que, apesar do incentivo à qualificação do professor em exercício na Educação Básica, houve um declínio da oferta dos cursos de licenciatura em geral, motivado pela baixa atratividade da carreira e pela precariedade nas condições de trabalho, o que dificulta a valorização do trabalhador docente e, em consequência, reduz a procura por esses cursos e pela profissão.

Com a implantação do Plano Nacional de Formação de Professores da Educação Básica (Parfor), pelo governo federal, por meio do Decreto no 6.755, de 29 de janeiro de 2009 (BRASIL, 2009a), confirma-se a tendência de fomentar a formação docente em serviço, uma das ações que se encontra entre as recomendações dos organismos multilaterais. O Parfor é um programa de responsabilidade da Coordenação de Aperfeiçoamento de Pessoal de Nível Superior (Capes), em colaboração com as Secretarias dos Estados, dos municípios e do Distrito Federal e com as instituições públicas de Educação Superior, universidades federais e estaduais e institutos federais. Conforme afirma Santos (2000), a formação em serviço é uma forma mais barata e eficiente de formar profissionais para a educação, em uma lógica que privilegia a relação custo-benefício, o que se revela compatível com um projeto de viés econômico bem como com uma visão técnica e instrumental de educação.

Dentro dessa lógica economicista, há igualmente o incentivo à redução no tempo de formação inicial e dos cursos de formação a distância. Esse entendimento se opõe ao daqueles que

[...] defendem melhorias no campo educacional, relacionando-as com o desenvolvimento de um projeto social, ligado a ideais democráticos, a formação inicial é valorizada na medida em que pode dotar os docentes de capacidade crítica e criadora, pelo estudo, pela discussão e pela análise do processo de ensinoaprendizagem e todos os seus condicionantes políticos, econômicos, sociais e culturais. (SANTOS, 2000, p. 174).

Existem diferentes entendimentos quando se trata de definir as políticas de formação docente, inclusive com relação à universidade como lócus preferencial de formação de professores, já que abrange o ensino, a pesquisa e a extensão, o que dificultaria a redução dos custos no processo de formação e do tempo em que essa ocorre. A alegação é de que, dado o contingente de professores a ser formado, o custo 
é demasiadamente alto, sobretudo se considerarmos a contínua e crescente necessidade de qualificação docente em nível superior.

Outro entendimento existente é o de que o foco da formação docente deva ser o conhecimento das disciplinas e de estratégias pedagógicas, favorecendo, assim, a instrumentalização docente para seguir normas e diretrizes curriculares, o que se revela incompatível com a formação universitária.

Além disso, observa-se a influência crescente das orientações dos organismos internacionais nas políticas de formação docente, o que não impede que outras influências também possam se fazer valer. Sobre o assunto, Cabral Neto e Castro (2011, p. 21) afirmam que "as decisões não ocorrem de forma unilateral; pelo contrário, são compartilhadas com as autoridades nacionais, havendo uma confluência de interesses e objetivos no campo político e econômico, assumindo características e peculiaridades locais". Isso significa dizer que diferentes atores sociais contribuem para que essas orientações se tornem predominantes.

$\mathrm{Na}$ perspectiva de uma melhor compreensão da expansão do Ensino Superior, procurou-se estabelecer relações entre a expansão da educação superior e os cursos de licenciatura. Neste artigo, há um recorte para fins de análise da relação das instituições universitárias com a expansão dos cursos de formação de professores na atualidade. Procurou-se pautar o documento a partir dos seguintes questionamentos: Que mudanças ocorreram em relação ao papel desempenhado pelas universidades no que diz respeito à formação de professores? Quais as características que diferenciam o processo de expansão nas universidades das demais instituições?

Os objetivos propostos estão voltados para a análise da expansão da educação superior no período pós-LDB, verificando as suas repercussões na formação de professores no Brasil, além da identificação dos formatos institucionais que se apresentam predominantes. Para isso, realizou-se estudo comparativo que tomou em consideração as realidades dos estados do Pará e do Rio Grande do Norte.

Com base na bibliografia anotada, construída no decorrer do projeto de pesquisa ao qual este estudo se vincula, foi feita uma revisão da literatura sobre a expansão do Ensino Superior, a organização institucional acadêmica e a formação de professores. Adicionalmente, foram elaboradas séries históricas que expressam a evolução do fenômeno em termos de crescimento das matrículas e vagas ofertadas, com referência ao período de 2003 a 2010, de forma a permitir uma melhor compreensão desse fenômeno nos dois mandatos do Governo Lula da Silva. 
A escolha desse período deveu-se às inúmeras iniciativas nas políticas educacionais no que diz respeito à formação de professores, já que as políticas até então adotadas não conseguiam alterar de forma significativa os índices de certificação docente em nível superior, o que seria desejável, sobretudo se considerarmos os compromissos internacionais assumidos pelo governo brasileiro para a melhoria da educação básica.

Para isso, recorreu-se à base de dados do Instituto Nacional de Estudos e Pesquisas Educacionais Anísio Teixeira (INEP) sobre a educação superior, além de consulta aos sítios das instituições universitárias nos dois estados. Foram observadas convergências e divergências no fenômeno estudado nos estados do Pará e do Rio Grande do Norte, com destaque para a expansão nas universidades, em comparação com outras formas de organização institucional.

\section{CENÁRIO DA EXPANSÃO DA EDUCAC̦ÃO SUPERIOR BRASILEIRA NO PERÍODO PÓS-LDB E A FORMAC̦ÃO DE PROFESSORES}

Pode-se dizer que tem havido mudanças nas relações entre universidade e sociedade, em que as funções clássicas de ensino, pesquisa e extensão que vinham norteando a constituição das universidades, convivem com funções de interesse mais imediato da sociedade. Segundo Sguissard (2004), observa-se uma ampliação do modelo neoprofissional das universidades, em que prevalece o ensino superior voltado à profissionalização. Em consequência, observa-se o enfraquecimento do chamado modelo neo-humboldtiano, em que predominam as universidades de pesquisa, que procuram associar o ensino à pesquisa universitária.

Essa situação pode ser mais bem explicitada a partir das análises desenvolvidas por Chesnais (1996, p.1), para quem as mudanças econômicas e sociais ocorridas nas quatro últimas décadas culminaram no "regime de acumulação com dominância de valorização financeira", o que trouxe implicações para as reformas institucionais na realidade brasileira, com a definição de um ambiente no qual predominam o controle dos gastos do Estado, o fim da regulação estatal e a liberdade máxima para o capital.

Dentro do conjunto de mudanças educacionais ocorridas no Brasil nas últimas duas décadas, ganhou força o processo de expansão da educação superior, fenômeno que vem se intensificando desde a década de 1990. Em sua materialização, o processo de expansão da educação superior brasileira se fez acompanhar de aparato legal ${ }^{6}$ com vistas a estimular, entre outros elementos, a diferenciação das 
instituições, a diversificação das modalidades de ensino e de cursos, o que vem impactando os índices da oferta de vagas, matrículas, cursos etc. (MANCEBO; BITTAR; CHAVES, 2012; GOMES; MORAES, 2012; FÁVERO; SGUISSARDI, 2012).

Essa expansão tem fortalecido a iniciativa privada, atualmente reunida em grandes conglomerados inseridos na Bolsa de Valores, o que evidencia a tendência à concentração institucional, à financeirização e à internacionalização desse nível de ensino Além disso, esse processo de expansão tem sido favorecido por meio da indução de políticas governamentais, como é o caso do Fundo de Financiamento Estudantil-FIES (BRASIL, 2001) e do Programa Universidade para Todos-Prouni (BRASIL, 2004; 2005), além do incentivo à formação de parcerias público-privadas.

No campo das políticas de expansão voltadas para o setor público, destaca-se o Programa de Apoio a Planos de Reestruturação e Expansão das Universidades Federais-Reuni (BRASIL, 2007a), programa federal voltado para a pactuação de metas, pelas Instituições de Federais de Educação Superior - IFES, no governo Lula da Silva que teve como diretrizes:

I - redução das taxas de evasão, ocupação de vagas ociosas e aumento de vagas de ingresso, especialmente no período noturno; II - ampliação da mobilidade estudantil, com a implantação de regimes curriculares e sistemas de títulos que possibilitem a construção de itinerários formativos, mediante o aproveitamento de créditos e a circulação de estudantes entre instituições, cursos e programas de educação superior; III - revisão da estrutura acadêmica, com reorganização dos cursos de graduação e atualização de metodologias de ensino-aprendizagem, buscando a constante elevação da qualidade; IV - diversificação das modalidades de graduação, preferencialmente não voltadas à profissionalização precoce e especializada; V- ampliação de políticas de inclusão e assistência estudantil; e VI - articulação da graduação com a pós-graduação e da educação superior com a educação básica.(BRASIL, 2007a).

Esse programa incentivou a expansão da oferta na graduação das IFES, com vistas a um "melhor aproveitamento da estrutura física e de recursos humanos existentes nas universidades federais" (BRASIL, 2007a). Para isso, essas IFES deveriam atender às diretrizes desse programa, para que fosse possível a ampliação de recursos financeiros adicionais, desde que os repasses fossem vinculados ao cumprimento das etapas.

Os estudos já desenvolvidos sobre a expansão da educação superior identificam suas principais tendências na realidade brasileira, como ampliação crescente do setor privado e da mercantilização desse nível de ensino, havendo, em consequência, mudança no padrão da educação superior. As instituições isoladas passam a 
ser predominantes, com a substituição do padrão de instituições universitárias centradas na oferta de ensino aliada à pesquisa e à extensão, modelo este que era a principal referência do sistema de educação superior na legislação anterior.

Em decorrência, modifica-se o tipo usual dessa oferta, anteriormente realizada predominantemente por universidades públicas, em geral voltadas para a formação de elites e para a produção do conhecimento e o desenvolvimento da cultura em geral (CABRAL NETO; CASTRO, 2011). O que se observa é o fortalecimento da oferta da educação superior em instituições privadas, em especial nas faculdades, em um movimento que tende a se acentuar em função das recentes políticas para esse nível de ensino após a aprovação da LDB.

Mancebo (2015) estabelece uma comparação na expansão da educação superior, considerando dois governos que se sucederam - o primeiro mandato do governo Fernando Henrique Cardoso (19951998) e o seu segundo mandato (1999-2002), quando 39,8\% das matrículas registradas ocorriam em IES públicas, e 60,2\%, nas privadas. Ao término dos mandatos, observou-se a redução da participação do setor público para 30,8\% e aumento do setor privado $(69,2 \%)$.

Essa tendência à privatização teve continuidade nos governos de Lula da Silva (2003-2006 e 2007-2010), com 25,8\% de matrículas, em IES públicas, e 74,2\%, em IES privadas. Foi comum aos dois governos o incentivo à ampliação do setor privado na oferta de educação superior, fosse por meio da expansão propriamente dita fosse mediante diferenciação e diversificação da oferta, com a retração desta última no setor público, considerando que as políticas governamentais secundarizaram, do ponto de vista financeiro, as chamadas políticas sociais.

\section{UNIVERSIDADES E FORMAC̦ÃO DE PROFESSORES: DIFERENTES OLHARES SOBRE A TEMÁTICA}

No século XX, um dos principais objetivos das instituições universitárias foi o de formar professores para atuar no ensino secundário, ficando o chamado ensino primário ${ }^{7}$ fora da missão da universidade durante muito tempo. Mais recentemente, com a ampliação da formação em nível superior de professores para a Educação Infantil e anos iniciais do Ensino Fundamental, verificase que há uma forte tendência ao desenvolvimento dessa tarefa em instituições isoladas de Ensino Superior e, preferencialmente, na modalidade a distância. 
Entre os autores que procuram analisar a formação de professores em nível superior, destacam-se Charlot e Silva (2010); Freitas (2007); Mindal e Guérios (2006); Lessard (2006); Maués e Camargo (2012); Silva e Castro (2007) e Zainko (2010), os quais apresentam elementos importantes na compreensão da atuação das universidades em relação ao foco aqui investigado.

Charlot e Silva (2010) direcionam sua análise com vistas a situar os desafios enfrentados pelas universidades contemporâneas em âmbito mundial, já que sugerem haver um conflito entre a centralidade da pesquisa e a formação dos professores. Sobre o assunto, indagam a respeito do destino dessa preparação para o magistério em universidades incitadas a focalizar a pesquisa, ao mesmo tempo em que discutem a continuidade dessa formação nessas instituições de ensino superior.

Uma das contribuições adicionais dos autores é a problematização das já tradicionais diferenças existentes nas universidades, a saber, a formação de professores para o ensino secundário - o Ensino Médio, na atual nomenclatura - e para o chamado ensino primário - atualmente, anos iniciais do Ensino Fundamental -, já que a formação do professor de ensino primário ficou de fora das missões das universidades, até pouco tempo atrás. A hipótese dos autores é a de que:

\footnotetext{
A própria natureza da universidade, tal como se construiu no decorrer da história, não condiz com as especificidades do ensino primário. No centro do ensino universitário encontra-se o professor, enquanto o processo de ensino/ aprendizagem primário focaliza o aluno. Ademais, o professor universitário sempre luta para sua autonomia, ao passo que o mestre-escola vive na dependência e o normalista, como indicado pelo seu próprio nome, é formado pela norma e para inculcar normas. Por fim, a universidade definiu-se por disciplinas, a tal ponto que, de fato, a universidade é um agrupamento de faculdades ou departamentos designados pela disciplina que ensinam. Ora, o docente que deve ensinar todas as disciplinas não se define por uma disciplina, mas pelo fato de que ele ensina a crianças. (CHARLOT; SILVA, 2010, p. 48).
}

Como sabido, a universidade esteve historicamente voltada para o ensino de disciplinas, o que estaria em conformidade com a formação de professores para o ensino secundário, diferentemente da formação de professores para os primeiros anos da escolarização.

Por fim, os autores analisam as principais evoluções contemporâneas da educação superior, como internacionalização, mercantilização e diferenciação, que acabam por imprimir uma forte pressão sobre as universidades que ainda restringem sua área de atuação em âmbito nacional ou local. 
As contribuições de Zainko (2010) dizem respeito à análise desenvolvida sobre as políticas de formação de professores na universidade pública, por meio das quais a autora procura construir argumentações que permitam compreender a relação entre o global e o local. Nesse sentido, ela situa aspectos das políticas de formação em desenvolvimento nas universidades, bem como as influências significativas no fazeracadêmico, trazidas pelas tendênciasinternacionais, no século XXI, quando se acentuou a influência da "mundialização" sobre os processos de formação na educação superior, os quais não podem mais ser pensados nos limites das fronteiras nacionais.

A autora analisa, ainda, a política de expansão da educação superior colocada em prática no governo Lula da Silva, além de apresentar as ações estratégicas que vêm sendo desenvolvidas para minimizar os déficits na escolarização e os desafios apresentados por estudiosos e dirigentes na Conferência Mundial de Educação Superior ocorrida no ano de 1999, com especial ênfase para o papel que a formação dos professores assume no momento atual. Segundo essa autora, a universidade precisa levar em consideração a inclusão de características inovadoras e ousadas nos processos de formação, que assegurem a qualidade social, o ensino superior como direito humano e bem público social, além da participação das comunidades interna e externa na construção de projetos político-pedagógicos comprometidos com os interesses e as necessidades das comunidades local, regional, nacional e internacional.

Outra análise aqui destacada é a de Lessard (2006), que parte do reconhecimento da centralidade do ensino superior para a formação de uma mão de obra altamente qualificada; entre outras coisas, o autor defende que essa mão de obra seja capaz de aprender coisas novas ao longo de sua vida profissional, o que acaba por suscitar uma maior intervenção do Estado e, mais globalmente, de grandes atores sociais; assim é que universidades, faculdades, departamentos e programas são submetidos a medidas de rendimento, de eficiência e eficácia (LESSARD, 2006, p. 202).

Mindal e Guérios (2006) procuram situar as principais questões abordadas acerca da formação de professores nas universidades públicas brasileiras com base em teses e dissertações do Banco da Capes, no período de 2006 a 2013. Nesse estudo, evidenciam a diversidade de problemas, impasses, dilemas e pontos de tensão que são conflitantes no campo da formação de professores. Entre as principais dificuldades, destaca-se a implementação de mudanças significativas nesses cursos, que acabam por valorizar de maneira desigual a pesquisa e o ensino, a pós-graduação se comparada 
à graduação, o bacharelado em relação à licenciatura, além dos problemas inerentes aos cursos de formação de professores das universidades públicas, como é o caso dos cursos noturnos. Outra questão igualmente importante diz respeito à pouca atratividade da carreira docente, o que pode favorecer a evasão nesses cursos, já que os alunos sentem-se desestimulados a prosseguir.

Segundo a produção analisada, houve uma ampliação do número de formados em áreas do conhecimento que tradicionalmente apresentavam dificuldades na conclusão do curso, como é o caso de biologia, química e física. Pode ter contribuído para tal a reestruturação curricular que abrangeu as licenciaturas e os bacharelados, além da redução da evasão de alunos de baixa renda, atribuída aos programas institucionais de bolsas de permanência. Esses fatores impactam sobremaneira a procura, a definição da oferta, bem como a constituição dos cursos de formação de professores nas universidades públicas brasileiras.

Ao comentar as recentes políticas de formação de professores no Brasil, Freitas (2007), identifica a má qualidade da formação que se desenvolve, a qual é comprometida ainda mais pela ausência de condições adequadas ao exercício do trabalho dos educadores. Esse fato não é restrito às políticas atuais e não é parte somente da realidade brasileira, mas está presente em toda a América Latina, como reflexo da queda do investimento público e da deterioração das condições de trabalho dos trabalhadores em educação. A autora defende uma política global de formação e valorização dos profissionais da educação que contemple, articulada e prioritariamente, a formação inicial, a formação continuada e as condições de trabalho, salários e carreira, o que não se materializa em uma sociedade marcada pela desigualdade e pela exclusão que acompanham o sistema capitalista.

A autora indica ainda a escassez de professores para a educação básica, que vem sendo apontada por diferentes autores e no relatório elaborado pelo Conselho Nacional de Educação, em julho de 2007. Trata-se assim de um problema estrutural que resulta da crescente "desresponsabilização" do Estado pela manutenção da educação pública bem como pela formação de seus educadores. Esse quadro se agrava com a proposição de alternativas conjunturais para enfrentar os problemas, como é o caso da complementação pedagógica em licenciaturas paralelas, do desenvolvimento de programas de formação dos professores leigos, em exercício e à distância, a criação do Programa Pró-licenciatura, em 2005, e da Universidade Aberta do Brasil (UAB), em 2006. Segundo a autora, essas medidas contribuem para aprofundar 
o quadro de desprofissionalização docente, seja pela flexibilização presente nos processos, seja pelo aligeiramento da formação.

$\mathrm{Na}$ abordagem desenvolvida por Silva e Castro (2007), as autoras procuram discutir as diretrizes da política de formação inicial de professores implantada no Brasil na década de 1990, que trouxeram novos direcionamentos e exigências tanto para as instituições formadoras quanto para o próprio processo de formação docente. Analisam, ainda, que a ampliação e a variação do lócus de formação docente têm levado a uma formação mais técnica e instrumental em detrimento de uma sólida formação teórico-prática. Esse é o caso dos Centros Federais de Educação Tecnológica (CEFET), transformados em institutos federais, que foram introduzidos também como lócus de formação. Segundo as autoras, essas instituições priorizam aspectos de natureza quantitativa, valorizam a otimização dos recursos e a instrumentalização da formação, mesmo que sob o discurso da qualidade do processo educacional.

Para as autoras, essa nova investida nos espaços de formação de professores, tarefa, antes, assumida prioritariamente pelas universidades, pode estar relacionada com a não adesão, sobretudo por universidades públicas, a importantes definições que se deram no campo de formação para o magistério; esse foi o caso da criação dos institutos superiores de educação e da rejeição à criação dos cursos normais superiores no âmbito universitário.

Adicionalmente, é importante mencionar que os cursos de licenciatura, assim como os demais cursos de graduação, vêm sendo estimulados a partir de iniciativas oficiais a desenvolver programas para a redução da evasão de alunos de baixa renda. São programas institucionais de bolsas de permanência, os quais igualmente contribuem para definir a procura, a oferta, bem como a conclusão dos cursos de formação de professores nas universidades públicas brasileiras.

\section{AS POLÍTICAS DE FORMAC̣ÃO DE PROFESSORES NO PERÍODO DE 2003 A 2010.}

Os estados do Pará e do Rio Grande do Norte já se constituíram em objeto de estudo sobre a expansão da educação superior pós-LDB, cujos resultados foram publicados em livro que analisa as políticas de expansão da educação superior no Brasil no período compreendido entre os anos de 1996 e 2008. (CABRAL NETO; NASCIMENTO; CHAVES, 2011). Nessa obra, priorizaram-se os casos dos estados do Maranhão, do Pará e do Rio Grande do Norte. 
Com base em dados do INEP, Chaves et al. (2011) apontam que o número de cursos de graduação, no estado do Pará tiveram um aumento de $213,2 \%$, predominando o setor privado, predominância essa que se dá, também, pelo aumento substancial do número de matrículas, atingindo $348 \%$, no período estudado, enquanto, no setor público, o percentual foi de $85,7 \%$.

No estudo mencionado, os autores constatam que o crescimento do número de instituições de ensino superior se deu, predominantemente, no setor privado, alcançando $800 \%$ no período estudado; no setor público, em contrapartida, foi de 66,7\%. Esse elevado crescimento do número de instituições ocorreu em faculdades, escolas e institutos superiores, formato organizacional estimulado pelo processo de expansão da educação superior brasileira, por ser menos oneroso e de mais fácil manutenção. Os dados, tanto no Pará quanto no Rio Grande do Norte, confirmam a tendência em curso na expansão da educação superior brasileira que privilegia a expansão do setor privado em formatos organizacionais considerados menos onerosos.

Procurou-se levantar dados relativos às matrículas em cursos de graduação, no Brasil, em geral, e as matrículas nos cursos de licenciatura, em particular, para que se pudesse perceber a evolução dessas matrículas em comparação com as observadas nos cursos em análise no período de 2003 a 2010. Esse levantamento está expresso no Gráfico 1, que possibilita entender melhor o cenário da expansão da educação superior e dos cursos de licenciatura em particular.

GRÁFICO 1 - Evolução das matrículas nos cursos de graduação e nas licenciaturas no Brasil

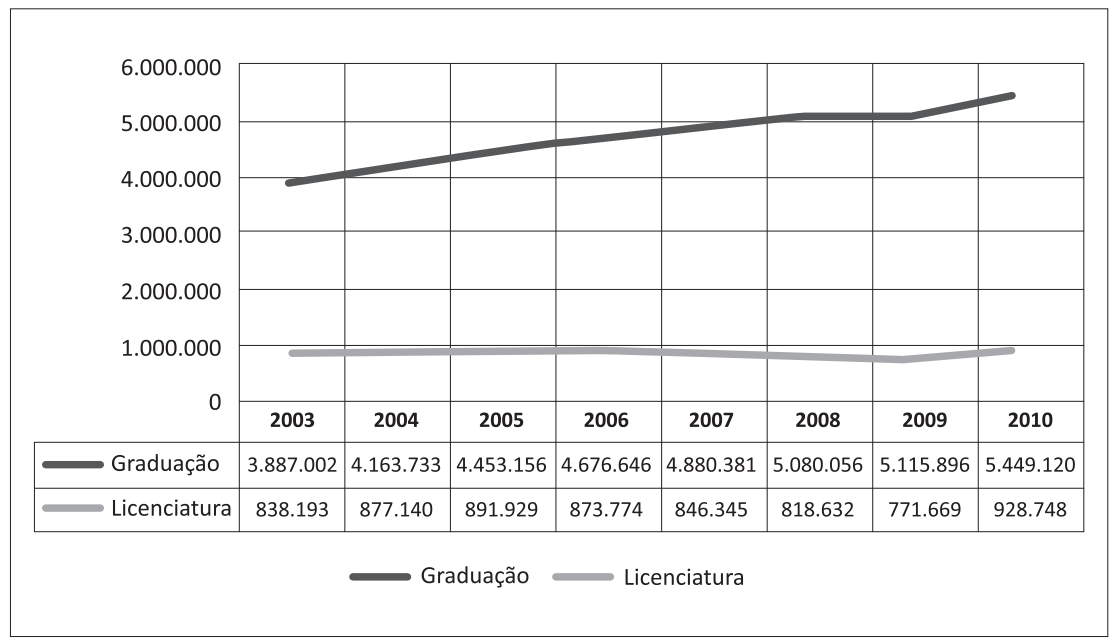

Fonte: MEC/INEP. Censo da Educação Superior 2014. ${ }^{8}$ 
É visível, no gráfico, um acentuado crescimento nas matrículas dos cursos de graduação em geral. Isso expressa a política de expansão levada a curso, no Brasil, resultante do conjunto de iniciativas apontadas anteriormente como o FIES, PROUNI e REUNI. Esses dados, se comparados às matrículas nos cursos de licenciaturas, registram um movimento diferenciado.

Em 2003 foram registradas 3.887.022 matrículas em cursos de graduação e 838.193, em cursos de licenciatura; estas últimas, percentualmente, representavam $21,6 \%$ do total das matrículas. No ano de 2010, as matrículas nos cursos de graduação chegaram a 5.449.120 e, em cursos de licenciatura, 928.748, o que representava, percentualmente, $17,1 \%$ do total de registros nesse ano. Se for tomado como referência o período analisado (2003-2010), o crescimento das matrículas nos cursos de licenciatura foi de apenas 10,8\%, enquanto o das matrículas nos cursos de graduação em geral foi de 40,2\%.

Há três momentos específicos da evolução das matrículas nos cursos de licenciatura no período em análise: o primeiro engloba os anos compreendidos entre 2003 (838.193 matrículas) e 2005 (891.929 matrículas), em que se verifica um crescimento na ordem de $6,41 \%$; um segundo momento, compreendido entre os anos 2006 (873.774 matrículas) e 2008 (818.632 matrículas), em que se verifica uma redução no crescimento das matrículas na ordem de 6,3\%; e um terceiro momento, entre 2009 (771.669 matrículas) e 2010 (928.749 matrículas), em que se registra um índice de crescimento nas matrículas na ordem de $20,4 \%$.

Para entender o crescimento ou a redução nas matrículas, é preciso referir-se às políticas do governo federal como é o caso do Prouni e do Fies, os quais privilegiam a renúncia fiscal, beneficiando as IES privadas. A exigência de ampliação na qualificação docente na educação básica resultou no aumento inicial da procura e na oferta de cursos de licenciatura, fato que pode ser comprovado com o crescimento das matrículas nos anos de 2003 a 2005.

Outra explicação para entender o crescimento das matrículas pode decorrer da aprovação das Resoluções $\mathrm{CNE} / \mathrm{CP} \mathrm{n}^{\circ}$ 01, de 18 de fevereiro de $2002^{9}$ (BRASIL, 2002a) e CNE/CP n ${ }^{\circ} 02$, de 19 de fevereiro de $2002^{10}$ (BRASIL, 2002b), por força das quais os cursos de licenciatura iniciaram o processo de separação dos cursos de bacharelado, com suas propostas pedagógicas desvinculadas destes últimos, o que, historicamente, ocorria de modo integrado, em um único curso, com raras exceções. Dessa forma, as matrículas 
nas licenciaturas, com aprovação de novos projetos pedagógicos, ocorreram separadamente dos cursos de bacharelado, o que pode ter influenciado os resultados apresentados.

Em relação à ampliação observada entre os anos de 2009 e 2010, há relação com matrículas registradas nos cursos ofertados pelo Programa de Formação de Professores da Educação Básica (Parfor), pelo REUNI, além da política de criação de novas IFES ocorrida inicialmente no governo Lula da Silva (2003-2010).

Entre os programas voltados para a formação de professores, destacam-se o Programa Pró-Licenciatura, o Plano de Metas Compromisso Todos pela Educação, o Plano de Ações Articuladas, e o Parfor - nas modalidades presencial e a distância. (GATTI; BARRETO; ANDRÉ, 2011).

O Plano de Metas Compromisso Todos pela Educação (Decreto $n^{\circ}$ 6.094/2007) estabeleceu diretrizes para a instituição de programa próprio ou em regime de colaboração para formação inicial e continuada de profissionais da educação a ser desenvolvido pelos estados, municípios e Distrito Federal (BRASIL, 2007a), bem como para implantação de plano de carreira, cargos e salários para esses profissionais. Esse decreto teve como desdobramento o Plano de Ações Articuladas (PAR), instrumento de planejamento da educação básica que visa oferecer apoio técnico e financeiro aos municípios brasileiros com índices insuficientes de qualidade de ensino, além de apresentar um caráter plurianual e multidimensional, com ênfase no regime de colaboração entre os entes federados. Abrange quatro dimensões do planejamento educacional: gestão educacional, formação de professores e dos profissionais de serviço e apoio escolar, práticas pedagógicas e avaliação, além de infraestrutura e recursos pedagógicos que foram objeto de diagnóstico a partir da implantação do PAR nos estados e municípios.

Os resultados desse diagnóstico contribuíram para a edição do Decreto no 6.755/2009 (BRASIL, 2009a), que definiu uma política nacional de formação objetivando a formação inicial e continuada dos professores em exercício, o Parfor, assumido centralmente pelas instituições públicas de ensino superior, universidades (federais e estaduais) e institutos federais.

A implantação do Parfor foi acompanhada da redefinição da atuação da Capes, que passou a assumir a responsabilidade pela indução à formação inicial de professores da educação básica. Além disso, a Capes ficou responsável pelo fomento a projetos de estudos, pesquisas 
e inovação caracterizados como programas voltados para a valorização do magistério ${ }^{11}$, como é o caso do Programa de Iniciação à Docência (Pibid), do Programa de Consolidação das Licenciaturas (Prodocência), do Programa de Apoio a Laboratórios Interdisciplinares de Formação de Educadores (Life) e do Observatório da Educação (Obeduc).

Outro destaque são as ações desenvolvidas pela Universidade Aberta do Brasil (UAB) ${ }^{12}$, criada pelo Ministério de Educação para unificar ações, programas, projetos, atividades em direção à expansão do oferecimento de Ensino Superior gratuito e de qualidade pelas instituições públicas, na modalidade a distância, com incentivo à colaboração entre a União e os entes federativos. Essas iniciativas, aliadas aos marcos regulatórios da educação superior no Brasil, irão compor o cenário no qual ocorreu a expansão dos cursos de formação de professores nos dois estados que são nosso objeto de estudo.

\section{A EXPANSÃO EM CURSOS DE LICENCIATURA NAS UNIVERSIDADES DO PARÁ E RIO GRANDE DO NORTE}

A expansão da educação superior no período de 2003 a 2010 será analisada nos estados do Pará e do Rio Grande do Norte, tendo como foco suas repercussões nos cursos de licenciaturas das universidades, uma das possíveis formas de organização institucional e acadêmica, além dos centros universitários, das faculdades e dos centros/institutos federais.

A organização institucional e acadêmica é definida por Morosini, Franco e Segenreich (2011, p. 119-140) como a que descreve "os tipos de Instituições de Educação Superior - IES mantidos e/ ou criados pelos documentos normativos surgido no período pósLDB/1996, incluídos as universidades, os centros universitários, as faculdades tecnológicas e as universidades tecnológicas, que servem de referência, dentre outros".

Segundo a Sinopse Estatística da Educação Superior (INEP, 2014), o estado do Pará contava, nesse ano, com 34 instituições de Ensino Superior, sendo seis universidades, apenas uma pertencente à rede privada, a Universidade da Amazônia (UNAMA). Desde 2014, a mantenedora dessa IES, passou a ser o grupo Ser Educacional, bolding ${ }^{13}$ que controla diversas instituições educacionais.

$\mathrm{Na}$ Sinopse foram registradas quatro universidades públicas, sendo uma estadual, a Universidade do Estado do Pará (UEPA), e quatro federais, a saber, Universidade Federal do Pará (UFPA), 
Universidade Federal Rural da Amazônia (UFRA), ambas com sede em Belém, Universidade Federal do Oeste do Pará (UFOPA), Universidade Federal do Sul e Sudeste do Pará (UNIFESPA), essas duas últimas resultantes do desmembramento da UFPA, a primeira no ano de 2009 e a segunda em 2013 e cujas sedes estão localizadas nas cidades de Santarém e Marabá respectivamente.

Em 2013, havia 25 instituições de educação superior no Rio Grande do Norte, sendo quatro universidades, apenas uma pertencente à iniciativa privada, no caso a Universidade Potiguar. Essa instituição integra o grupo Laureate International Universities, conglomerado norte-americano presente em 28 países nas Américas, Europa, Ásia, África e Oriente Médio, instituição que, assim como outras, segue a tendência internacional de mercantilização educacional, com fusões e aquisições de empresas nacionais.

O segmento universitário, no estado, é composto, ainda, de três universidades públicas, sendo duas universidades federais, a saber, a Universidade Federal do Rio Grande do Norte (UFRN) e a Universidade Federal Rural do Semi-Árido (UFERSA) ${ }^{14}$ criada em 2005, e uma universidade estadual, a Universidade do Estado do Rio Grande do Norte (UERN), criada em 1968, na cidade de Mossoró, possuindo campi e núcleos avançados em várias cidades desse estado.

Apesar das especificidades de cada estado, observa-se em ambos a predominância de universidades públicas federais, as quais realizaram um movimento de interiorização da educação superior, com a criação de novas instituições que fogem ao modelo tradicional da sede na capital do estado.

Nas universidades particulares registradas, está presente a tendência observada nacionalmente de mercadorização da educação, de sucessivas aquisições e fusões de instituições educacionais. Segundo Sguissardi (2008), trata-se de um "fenômeno que antes era próprio do mercado financeiro, industrial e comercial: a presença de grandes fundos de investimento no chamado mercado educacional do país, como já ocorre em alguns outros países do centro e da periferia global" (SGUISSARDI, 2008, p. 1003).

A Tabela 1, abaixo, expressa o crescimento das matrículas nos cursos de licenciatura nos dois estados, considerando-se a organização acadêmica e institucional. 
TABELA 1 - Crescimento de matrículas nas licenciaturas por organização acadêmica no Pará(PA) e Rio Grande do Norte (RN)- 2003 a 2010

\begin{tabular}{|c|c|c|c|c|c|c|c|c|}
\hline \multirow[t]{2}{*}{ ANO } & \multicolumn{2}{|c|}{ UNIVERSIDADE } & \multicolumn{2}{|c|}{$\begin{array}{c}\text { CENTRO } \\
\text { UNIVERSITÁRIO }\end{array}$} & \multicolumn{2}{|c|}{ FACULDADE } & \multicolumn{2}{|c|}{$\begin{array}{c}\text { CENTRO/ } \\
\text { INSTITUTO FEDERAL }\end{array}$} \\
\hline & PA & RN & PA & RN & PA & RN & PA & $\mathbf{R N}$ \\
\hline 2003 & 21.959 & 10.855 & 1.049 & 311 & 314 & 361 & 829 & 55 \\
\hline 2004 & 23.088 & 9.858 & 1.718 & 255 & 947 & 403 & 1.224 & 96 \\
\hline 2005 & 23.925 & 9.327 & 1.789 & 519 & 1.256 & 292 & 289 & 195 \\
\hline 2006 & 23.608 & 9.774 & 2.239 & 993 & 1.406 & 433 & 532 & 208 \\
\hline 2007 & 22.038 & 9.056 & 2.382 & 1.004 & 1.412 & 567 & 627 & 296 \\
\hline 2008 & 22.381 & 8.589 & 772 & * & 3.515 & 1.364 & 757 & 368 \\
\hline 2009 & 18.564 & 12.828 & 783 & * & 2.215 & 1.020 & 1.362 & 722 \\
\hline 2010 & 25.740 & 12.685 & 658 & * & 3.182 & 1.057 & 653 & 1.007 \\
\hline $\begin{array}{c}2003-2010 \\
\Delta \%\end{array}$ & 17,2 & 16,9 & $\cdot 37,3$ & * & 913,4 & 192,8 & $.21,2$ & 1730,9 \\
\hline
\end{tabular}

*Dados não disponibilizados

Fonte: INEP, Microdados 2015.

No estado do Pará, em 2003, as matrículas em cursos de licenciatura totalizavam 24.151, das quais 21.959 eram em universidades, representando $90,9 \%$ do total de registros de matrículas. No ano de 2010, 30.233 matrículas foram registradas em cursos de licenciatura, sendo 25.740 matrículas em universidades, o que correspondia a $85,1 \%$ do total, havendo, assim, um pequeno decréscimo em relação ao ano de 2003.

No estado do Rio Grande do Norte, foram registradas 11.582 matrículas em cursos de licenciatura no ano de 2003; dessas, 10.855 foram em universidades, o que correspondia a $93,7 \%$ do total ofertado. Em 2010, havia 14.749 matrículas em cursos de licenciatura, das quais 12.685 foram registradas em universidades, o que correspondia a $86 \%$ do total, verificando-se uma discreta redução das matrículas, o que também foi observado no estado do Pará.

No segmento universidades, a variação percentual em relação ao crescimento das matrículas tanto no estado do Pará $(17,2 \%)$ quanto no estado do Rio Grande do Norte (16,9\%) foi evidente; esse crescimento decorreu das políticas federais de indução da expansão que impactaram não só as universidades públicas, mas igualmente as instituições universitárias do setor privado. No caso específico das universidades públicas, o número das matrículas guarda relação com o REUNI e o PARFOR (iniciado a partir de 2009). 
Essa constatação evidencia a importância das políticas concebidas pelo governo federal, a partir de 2005. Importante lembrar que a ampliação do contingente de docentes qualificados em nível superior é considerada como um dos elementos fundamentais para a melhoria do desempenho da educação básica.

Se comparados os anos de 2003 e 2010, verifica-se que o maior crescimento nas matrículas foi observado nos Centros/Institutos Federais no Rio Grande do Norte $(1.730,9)$, seguido das Faculdades no Pará $(913,4)$. Destaca-se ainda uma redução das matrículas nos Centros Universitários no Pará; no caso do Rio Grande do Norte, desde 2008 não há registro de vagas nessa forma de organização acadêmica, o que indica a opção por outros cursos de graduação que não as licenciaturas.

Além da participação do segmento universitário, verifica-se que a variação percentual em relação às matrículas no período em análise foi evidente nas faculdades, no Pará $(913,4)$, e em Instituto Federal, no Rio Grande do Norte $(1.730,9)$. Entre as possíveis explicações desse índice nas faculdades está o incentivo à expansão no setor privado, face à isenção fiscal que beneficia esse setor. No caso dos cursos de licenciatura, a sua implantação é de baixo custo, e não implica substancialmente em investimentos financeiros.

Em relação ao caso dos institutos federais, como já apontado anteriormente, eles passaram a se constituir como lócus de formação de professores, conforme assinalam Otranto (2015) e Silva e Castro (2007). É importante lembrar que, desde 2007, a partir do Decreto $n^{\circ}$ 6.095/2007 (BRASIL, 2007), os institutos federais de educação superior criados deveriam, entre outros, ministrar cursos de licenciatura, bem como programas especiais de formação pedagógica, com vistas à formação de professores para a educação básica.

Os números apresentados podem ter sofrido influências das opções metodológicas do trabalho realizado pelo INEP ${ }^{15}$, já que, entre os anos de 2003 e 2008, na Sinopse Estatística divulgada, o número de matrículas por curso não está discriminado em cursos de licenciaturas por estados. A terminologia utilizada nesse período - área de Educação - englobava cursos de formação de professores propriamente ditos e também cursos de Ciências da Educação, os quais nem sempre incluíam a formação em uma licenciatura propriamente dita, como é o caso do Bacharelado em Pedagogia então existente.

Ao lado disso, com a aprovação da Resolução $\mathrm{CNE} / \mathrm{CP} \mathrm{n}^{\circ}$ 001/2002, que estabeleceu Diretrizes para a Formação Inicial de Professores da Educação Básica em nível superior, curso de licenciatura 
de graduação plena, os projetos pedagógicos de cursos de licenciatura passaram a ser concebidos separadamente de cursos de bacharelado, o que pode ter se refletido nos dados estatísticos divulgados.

Outro elemento a ser analisado diz respeito à oferta de vagas, a qual será igualmente destacada a questão das licenciaturas nos dois estados.

TABELA 2 - Crescimento das vagas em cursos de licenciatura segundo a organização acadêmica nos estados do Pará (PA)e Rio Grande do Norte(RN) - 2003 a 2010

\begin{tabular}{|c|c|c|c|c|c|c|c|c|}
\hline \multirow[t]{2}{*}{ ANO } & \multicolumn{2}{|c|}{ UNIVERSIDADE } & \multicolumn{2}{|c|}{$\begin{array}{c}\text { CENTRO } \\
\text { UNIVERSITÁRIO }\end{array}$} & \multicolumn{2}{|c|}{ FACULDADE } & \multicolumn{2}{|c|}{$\begin{array}{c}\text { CENTRO/INSTITUTO } \\
\text { FEDERAL }\end{array}$} \\
\hline & PA & RN & PA & RN & PA & RN & PA & RN \\
\hline 2003 & 2.730 & 1.344 & 600 & - & 557 & 370 & 400 & 60 \\
\hline 2004 & 4.917 & 1.675 & 1.280 & 80 & 661 & 370 & 280 & 60 \\
\hline 2005 & 3.570 & 1.496 & 840 & 40 & 1.495 & 300 & * & \\
\hline 2006 & 3.469 & 1.724 & 1.440 & 140 & 1.160 & 590 & * & 42 \\
\hline 2007 & 2.075 & 1.454 & 500 & * & 1.729 & 490 & 282 & 177 \\
\hline 2008 & 3.892 & 1.429 & 619 & * & 3.121 & 840 & 320 & 185 \\
\hline 2009 & 4.502 & 3.527 & 640 & * & 2.815 & 875 & 360 & 449 \\
\hline 2010 & 4.473 & 4.135 & 440 & * & 3.195 & 980 & 280 & 560 \\
\hline $\begin{array}{c}2003 \cdot \\
2010 \Delta \%\end{array}$ & 63,8 & 207,6 & $-26,7$ & * & 473,6 & 164,9 & $-30,0$ & 833,3 \\
\hline
\end{tabular}

*Dados não disponibilizados

Fonte: INEP, Microdados 2015.

No período em análise, a variação percentual das vagas nas universidades no Pará foi de 63,8 e no Rio Grande do Norte foi 207,6 , o que pode indicar que nesses estados a tarefa de formação de professores ainda é prioritária.. Ao lado disso, observa-se uma crescente ampliação das vagas em Institutos Federais, caso do RN, e em Faculdades, especialmente no estado do PA, o que confirma os índices já observados nas matrículas.

Se tomarmos como referência o ano de 2010, verificarse que, no estado do Pará, foram ofertadas 8.168 vagas em cursos de licenciatura, destas, 4.473 vagas foram em universidades, o que representa 54,7\% do total. No Rio Grande do Norte, foram ofertadas 5.675 vagas, das quais $72,7 \%$ ocorreram em universidades, representando a maior parte da oferta, assim como no Pará.

No processo de expansão analisado, verifica-se um crescimento das vagas no segmento das faculdades, as quais são as que, ao lado das universidades, ofertam o maior número de vagas 
nas licenciaturas. Como esses cursos em geral são ofertados por IES privadas, há relação entre esse crescimento e a indução da expansão do setor privado através de políticas de isenção fiscal, além do baixo investimento necessário para a criação de cursos de licenciatura.

A variação percentual quanto às vagas ofertadas em universidades no período de 2003 a 2010, tanto no estado do Pará $(63,8)$ como no Rio Grande do Norte $(207,6)$, decorre da criação de instituições universitárias no interior dos estados. No Pará, destaca-se a criação da UFOPA, com sede na cidade de Santarém, que abrigava campus da UFPA. No Rio Grande do Norte, destaca-se a UFERSA, localizada na cidade de Mossoró, já mencionada; essas duas IES foram criadas a partir do processo de criação de novas IFES por iniciativa do governo Lula da Silva.

Outra explicação está relacionada à oferta de vagas em cursos de formação de professores em exercício, como o Programa Especial de Formação de Professores em Exercício (Proformação) ${ }^{16}$, criado em 1999, resultado de convênio entre a Universidade do Estado do Rio Grande do Norte (UERN) e a Secretaria de Estado de Educação e Cultura (SEEC), do estado do Rio Grande do Norte. Esse programa durou até 2009, ano em que foi substituído pelo Parfor. No caso do Pará, segundo dados da Capes de $2013^{17}$, é o estado que apresenta maior número de turmas desse programa, o que poderá redefinir o perfil docente nesse estado no que diz respeito ao nível da formação do docente da educação básica.

Além disso, com a criação do Reuni, programa federal de indução da expansão nas IFES, houve incentivo à ampliação das modalidades dos cursos de graduação, além da elevação da taxa de conclusão dos cursos de graduação.

\section{CONSIDERACְ̃̃ES FINAIS}

As novas demandas por qualificação dos profissionais da educação, intensificadas no final do século passado, alargaram as possibilidades de desenvolvimento de cursos de licenciatura. Essa situação foi particularmente observada tendo em vista a necessidade de qualificar os profissionais que atuam na educação infantil e nos anos iniciais da escolarização, tarefa assumida em cursos de nível médio. Essa exigência teve implicações importantes na expansão da educação superior.

Isso difere de situações anteriores, do século passado, quando as universidades assumiram centralmente a formação de professores para o ensino secundário, tendência indicada por Charlot e Silva (2010). 
Esses autores situam os desafios enfrentados pelas universidades contemporâneas em âmbito mundial; apontam o conflito entre a formação de professores e a centralidade da pesquisa (própria da instituição universitária), além das especificidades que envolvem a formação de professores para as etapas iniciais da escolarização, que, no entendimento dos autores acima mencionados, não condiz com a natureza da formação universitária.

Apesar dessas constatações, a presença desses cursos de formação de professores na instituição universitária pode ser um diferencial a mais em relação ao desenvolvimento de ações estratégicas para minimizar os déficits na escolarização. Isso exige uma ressignificação dos espaços de formação, já que se trata de cursos com especificidades que precisam ser consideradas na gestão dessas IES.

No período de 2003 a 2010, em relação à expansão nos cursos de licenciatura nos estados analisados, pode-se dizer que, a maior parte das matrículas ainda ocorre nas universidades, tanto no estado do Pará quanto no Rio Grande do Norte. Isso indica que a prioridade na formação de professores ainda se mantém nessa forma de organização acadêmica, o que a nosso ver é positivo.

Ao lado disso, constata-se uma tendência crescente à ampliação das matrículas em faculdades, centros e institutos federais. Isso vem corroborar o entendimento de que a centralidade da formação de professores é dividida com outras IES, o que contribui para a diversidade da formação de professores, já que elas apresentam diferentes missões institucionais, com essas modalidades acadêmicas sendo compostas em muitos casos por instituições que não têm tradição nessa formação.

Em relação às vagas ofertadas, constata-se, pelos números apresentados, que tanto no Pará, quanto no Rio Grande do Norte, o crescimento se mantém, ao lado da crescente ampliação das vagas em institutos federais, caso do RN, e em faculdades, nos dois estados, o que confirma o crescimento já observado nas matrículas.

No estado do Pará, mais da metade das vagas ofertadas em cursos de licenciaturas foi em universidades, o que não foi diferente da realidade do estado do Rio Grande do Norte; isso reforça o entendimento de que a formação inicial de professores ainda é central nesses estados. Ao lado disso, vem se observando uma variação percentual importante no segmento das faculdades, cursos em geral ofertados por IES privadas. Pode-se dizer que se confirma a relação entre esses índices e a indução da expansão do setor privado através de políticas de isenção fiscal, caso do FIES e PROUNI. 
As iniciativas emergenciais, comoé o caso do Parfor, contribuíram igualmente para a ampliação da oferta de vagas e do número de matrículas nas universidades públicas, sobretudo nos últimos anos da série histórica estudada, 2009 e 2010. Além disso, o Reuni igualmente contribuiu para a indução da expansão nas IFES, inclusive na criação das novas IFES; houve incentivo à ampliação das modalidades dos cursos de graduação, o que pode possibilitou a ampliação das vagas e matrículas observadas nos últimos anos da série analisada.

Em síntese, com o crescimento do sistema de educação superior e as crescentes demandas por formação docente nesse nível de ensino, além do estímulo à diversificação institucional, o processo de formação docente passou a ser assumido por outras instituições, além das universidades nos dois estados, Pará e Rio Grande do Norte.

De um lado, essa constatação permite uma divisão de responsabilidades na tarefa de formar professores, e, em consequência, o aumento da qualificação docente para a educação básica nesses estados; por outro lado, pode representar um complicador a mais nessa complexa tarefa, sobretudo se considerarmos a população que tradicionalmente integra o corpo discente desses cursos.

Por último, nos estados analisados, reafirma-se o papel preponderante a ser desempenhado pelas instituições universitárias, apesar das dificuldades enfrentadas por essas IES nessa tarefa formativa, sobretudo nas instituições federais, já que elas vêm sendo induzidas a utilizar parâmetros mais próximos da otimização de recursos, critério nem sempre o mais adequado quando se trata do campo de formação de professores.

\section{REFERÊNCIAS}

BRASIL. Lei no 9.394, de 20 de dezembro de 1996. [LDB]. Estabelece as Diretrizes e Bases da Educação Nacional. Diário Oficial da União, Brasília, Ano CXXXIV, n. 248, p. 2783327.841, 23 dez.1996.

Decreto $n^{\circ} 5.773$, de 9 de maio de 2006. Dispõe sobre o exercício de funções e regulação, supervisão e avaliação de instituições de educação superior, cursos superiores de graduação e sequenciais no sistema federal de ensino. Disponível em <http://www4.mec. gov.br/sapiens/portarias/dec5773.htm>. Acesso em 10 de março de 2015.

Decreto $\mathrm{n}^{\circ}$ 6.094, de 24 de abril de 2007. Dispõe sobre a implementação do Plano de Metas Compromisso Todos pela Educação, pela União Federal, em regime de colaboração com Municípios, Distrito Federal e Estados, e a participação das famílias e da comunidade, mediante programas e ações de assistência técnica e financeira, visando a mobilização social pela melhoria da qualidade da educação básica. Diário Oficial da União. Brasília, 25 abr. 2007a. Disponível em: <http://www.planalto.gov.br/ccivil_03/_ato20072010/2007/decreto/d6094.htm>. Acesso em: 12 maio 2015. 
Decreto $n^{\circ}$ 6.755, de 29 de janeiro de 2009 [2009a]. Institui a Política Nacional de Formação de Profissionais do Magistério da Educação Básica, disciplina a atuação da Coordenação de Aperfeiçoamento de Pessoal de Nível Superior - CAPES no fomento a programas de formação inicial e continuada, e dá outras providências. Diário Oficial da União. Brasília, 30 jan. 2009a. Disponível em: < http://www.planalto.gov.br/ccivil_03/_ ato2007-2010/2009/decreto/D6755impressao.htm>. Acesso em: 10 maio 2015.

. Lei no 11.096, de 13 de janeiro de 2005. [Conversão da MPv no 213, de 2004]. Institui o Programa Universidade para Todos - PROUNI, regula a atuação de entidades beneficentes de assistência social no ensino superior; altera a Lei no 10.891 , de 9 de julho de 2004, e dá outras providências. Diário Oficial da União. Brasília, 14 jan. 2005. Disponível em: <http://www.planalto.gov.br/ccivil_03/_Ato2004-2006/2005/Lei/L11096.htm>. Acesso em: 23 set. 2014.

. Lei no 10.260, de 12 de julho de 2001. [Conversão da MPv nº 2.094-28, de 2001]. Dispõe sobre o Fundo de Financiamento ao estudante do Ensino Superior e dá outras providências. Diário Oficial da União. Brasília, 13 jul. 2001. Disponível em: <http://www. planalto.gov.br/ccivil_03/Leis/LEIS_2001/L10260.htm>. Acesso em: 12 set.-2015.

. Lei no 11.494/2007b, de 20 de junho de 2007. Regulamenta o Fundo de Manutençãoe Desenvolvimento da Educação Básica e de Valorização dos Profissionais da Educação -FUNDEB, de que trata o art. 60 do Ato das Disposições Constitucionais Transitórias; altera a Lei $\mathrm{n}^{\circ}$ 10.195, de 14 de fevereiro de 2001; revoga dispositivos das Leis nos 9.424, de 24 de dezembro de 1996, 10.880, de 9 de junho de 2004, e 10.845, de 5 de março de 2004; e dá outras providências. Disponível em: < http://www.planalto.gov.br/ccivil_03/_ato20072010/2007/lei/111494.htm>. Acesso em: 12 set. 2014.

Lei no 9.424, de 24 de dezembro de 1996b. Dispõe sobre o Fundo de Manutenção e Desenvolvimento do Ensino Fundamental e de Valorização do Magistério, na forma prevista no art. $60, \int 7^{\circ}$, do Ato das Disposições Constitucionais Transitórias, e dá outras providências. Disponível em http://www2.camara.leg.br/legin/fed/lei/1996/lei-9424-24dezembro-1996-365371-norma-pl.html. Acesso em 10 de março de 2015.

. Ministério da Educação (MEC). Conselho Nacional de Educação (CNE). Resolução CNE/CP no 001/2002, de 18 de Fevereiro de 2002. Institui Diretrizes Curriculares Nacionais para a Formação de Professores da Educação Básica, em nível superior, curso de licenciatura, de graduação plena. Diário Oficial da União, Brasília, 9 de abril de 2002a. Seção 1, p. 31. Republicada por ter saído com incorreção do original no D.O.U. de 4 de março de 2002. Seção 1, p. 8. Disponível em: <http://portal.mec.gov.br/cne/arquivos/ pdf/CP012002.pdf>. Acesso em: 12 abr. 2015.

- Ministério da Educação (MEC). Conselho Nacional de Educação (CNE). Resolução CNE/CP n ${ }^{\circ}$ 02/2002, de 19 de fevereiro de 2002. Institui a duração e carga horária dos cursos de formação professores da educação básica, em nível superior. Brasília, 2002b. Disponível em < http://portal.mec.gov.br/cne/arquivos/pdf/CP022002.pdf>. Acesso em 12 de abril de 2015.

. Ministério da Educação (MEC). Diretrizes gerais do Decreto 6.096 - REUNI -Reestruturação e Expansão das Universidades Federais, de 24 de abril de 2007. Disponível em < http://portal.mec.gov.br/sesu/arquivos/pdf/diretrizesreuni.pdf > . Acesso em 22 de janeiro de 2015.

CABRAL NETO, A.; CASTRO, A. M. A. A supremacia da iniciativa privada na expansão do ensino superior: realidade brasileira e repercussões no RN. In: CABRAL NETO, A.; NASCIMENTO, I. V. do; CHAVES, V. L. J. Política de expansão da educação superior 
no Brasil: democratização às avessas. São Paulo: Xamã, 2011. p. 15-38.

CABRAL NeTO, A.; NASCIMENTO, I. V. do; CHAVES, V. L. J. Política de expansão da educação superior no Brasil: democratização às avessas. São Paulo: Xamã, 2011.

CHARLOT, B.; SILVA, V. A. da. De Abelardo até a classificação de Xangai: as universidades e a formação dos docentes. Educar em Revista, Curitiba, n. 37, p. 39-58, mai.-ago. 2010

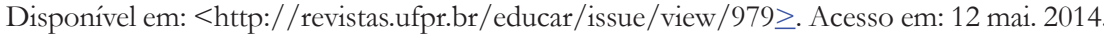

CHAVES, V. L. J. et al.. A Expansão da educação superior no Pará: cenário atual e tendências. In: CABRAL NETO, Antonio; CHAVES, Vera Lúcia Jacob; NASCIMENTO, Ilma Vieria do. (Org.). Política de expansão da educação superior no Brasil: democratização às

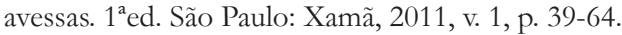

CHESNAIS, F. A globalização e o curso do capitalismo de fim-de-século. Economia e Sociedade, Campinas, n. 5, p.1-30, dez. 1995.

FÁVERO, M. L. de A. A Universidade no Brasil: das origens à reforma universitária de 1968. Educar, Curitiba, n. 28, p. 17-36, 2006.

FÁVERO, M. L. de A; SGUISSARDI, V. Quantidade/qualidade e educação superior. Educação em Questão, Natal, v. 42, n. 28, p. 61-88, jan./abr. 2012.

FREITAS, H. L. de. A (nova) política de formação de professores: a prioridade postergada. Educação \& Sociedade, Campinas, v. 28, n. 100, p. 1203-1230, out. 2007. Disponível em:

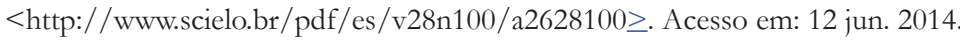

GATTTI, B. A.; BARreto, E. S. de S.; ANDrÉ, M. E. D. de A. Políticas docentes no Brasil: um estado da arte. Brasília: UNESCO, 2011.

GOMES, A. M.; MORAES, K. N. de. Educação superior no Brasil contemporâneo. Transição para um sistema de massa. Educação \& Sociedade, Campinas, v. 33, n. 118, p. 171-190, jan./mar. 2012. Disponível em: <http://www.scielo.br/pdf/es/v33n118/ v33n118a11.pdf>. Acesso em: 21 dez. 2013.

INEP - Instituto Nacional de Estudos e Pesquisas Educacionais Anísio Teixeira. Página Inicial. Censo do Professor 1997. Perfil dos docentes da Educação Básica. Brasília: INEP, 1999. $150 \mathrm{p}$

Censo da Educação Superior 2014: Principais Resultados. Brasília, 2014. Disponível em: <http://download.inep.gov.br/educacao_superior/censo_superior/ documentos/2015/censo_da_educacao_superior_2014_principais_resultados.xls > . Acesso em agosto de 2015 .

LESSARD, C. A Universidade e formação profissional dos docentes: novos questionamentos. Educação \& Sociedade, Campinas, v. 27, n. 94, p. 201-227, jan/abr. 2006.

MANCEBO, D.; BITTAR, M.; CHAVES, V. L. J. Org.). Educação Superior: expansão e reformas educativas. Maringá: Eduem, 2012.

MANCEBO, D. Políticas de educação superior no Brasil. In: SILVA JÚNIOR, J. dos R. et al. (Org.). Educação Superior: Internacionalização, mercantilização e repercussões em um campo de disputa. Belo Horizonte: Fino Traço, 2015. p.141-161.

MAUÉS, O. C.; CAMARGO, A. M. M. de. Marcos regulatórios nas políticas de formação e valorização docente pós-LDB. Educação em Questão. Natal, v. 42, n. 28, p. 149-174, jan./ abr. 2012.

McCOWAN, T.; S.; SCHENDEL, R. A mudança do papel da universidade e seu impacto na sociedade em países de baixa renda. In: SILVA JÚNIOR, José dos Reis da et al. (Org.). Educação Superior: internacionalização, mercantilização e repercussões em um campo de 
disputa. Belo Horizonte: Fino Traço, 2015. p. 19-48.

MINDAL, C.; GUÉRIOS, E. Formação de professores em instituições públicas de ensino superior no Brasil: diversidade de problemas, impasses, dilemas e pontos de tensão. Educar em Revista, Curitiba, n. 50, p. 21-33, out-dez. 2013.

MOROSINI, M.; FRANCO, M. E. D. P.; SEGENREICH, S. C. D. A expansão da educação superior no Brasil pós-LDB/96: organização institucional e acadêmica. Inter-Ação, Goiânia, v. 36, n. 1, p.119-140, jan-jun. 2011.

OLIVEIRA, M. B. de. As contribuições do Proformação Pedagogia UERN para a melhoria da prática pedagógica dos professores. 2010. 52 f. Dissertação (Mestrado em Educação) - Centro de Educação, Universidade Federal do Rio Grande do Norte, Natal, $\mathrm{RN}, 2010$.

SANTOS, L. L. C. A implementação de políticas do Banco Mundial para a formação docente. Cadernos de Pesquisa, n. 111, p. 173-182, dezembro/2000.

SOUSA, A. Q. de. Universidade Aberta do Brasil (UAB) como política de formação de professores. Revista Educação em Questão, Natal, v. 42, n. 28, p. 119-148, jan./abr. 2012.

ZAINKO, M. A. S. Políticas de formação de professores na universidade pública: uma análise de necessidades, entre o local e o global. Educ. Rev, [online]. 2010, n.37, pp.113-127-127.

\section{NOTAS}

${ }^{1}$ Projeto em desenvolvimento desde 2012 pela Rede Universitas/Br e vinculado ao Observatório da Educação (OBEDUC/CAPES).

${ }^{2}$ A terminologia ensino secundário, que vigorou no Brasil, corresponde aos atuais segmento do Ensino Fundamental (anos finais) e Ensino Médio.

${ }^{3}$ Os níveis escolares previstos pela LDB são a educação básica e a educação superior. A educação básica inclui a Educação Infantil, o Ensino Fundamental e Ensino Médio. No estudo referido, Censo do Professor/1999, o INEP manteve a terminologia $1^{\circ}$ grau por se tratar de dados relativos ao ano de 1997, primeiro ano de implantação da nova lei.

${ }^{4}$ Instituído pela Emenda Constitucional no 14/1996 (BRASIL, 1996).

${ }^{5}$ Lei no 11.494/2007 (BRASIL, 2007b).

${ }^{6}$ É o caso do Decreto no 5.773, de 9 de maio de 2006 (BRASIL, 2006), que dispõe sobre o exercício das funções de regulação, supervisão e avaliação de instituições de educação superior, cursos superiores de graduação e sequenciais no sistema federal de ensino.

${ }^{7} \mathrm{O}$ ensino primário correspondia aos atuais anos iniciais do Ensino Fundamental.

${ }^{8}$ Disponível em: <http://download.inep.gov.br/educacao_superior/censo_superior/ documentos/2015/censo_da_educacao_superior_2014_principais_resultados.xls >. Acesso em: 13 ago. 2015.

${ }^{9}$ Instituiu Diretrizes Curriculares Nacionais para a formação de professores da Educação Básica, em nível superior, curso de licenciatura, de graduação plena.

${ }^{10}$ Instituiu a duração e a carga horária dos cursos de licenciatura, de graduação plena, de formação de professores da Educação Básica em nível superior.

${ }^{11}$ Disponível em: <www.capes.gov.br/educacaobasica>. Acesso em: 23 mar. 2016.

${ }^{12}$ Sobre o assunto, ler Sousa (2012).

${ }^{13}$ Controladora da Uninassau, das Faculdades Maurício de Nassau e Joaquim Nabuco, das 
Escolas Técnicas Maurício de Nassau e Joaquim Nabuco, do Bureau Jurídico, do Instituto de Pesquisa Maurício de Nassau e do Instituto Ser Educacional.

${ }^{14}$ A UFERSA resultou das sucessivas transformações que se deram na Escola de Agricultura de Mossoró, criada em 1967.

${ }^{15}$ Até o ano de 2008, os dados divulgados pelo INEP incluíam a soma dos semestres. A partir de 2009, indicavam apenas as informações relativas ao $1^{\circ}$ semestre de cada ano. Nas tabelas apresentadas, utilizaram-se dados relativos ao $1^{\circ}$ semestre de cada ano.

${ }^{16}$ Sobre o assunto, ver Oliveira (2010). Disponível em: <http://repositoriao.ufrn/jspui/ bitstream/123456789/14418/1/MarciaBO_DISSET.pdf>. Acesso em: 12 jan. 2015.

17 Dados disponíveis em: <www.capes.gov.br/educacaobasica/parfor>. Acesso em: 21 dez. de 2014.

Submetido: 30/03/2016

Aprovado: 26/08/2016

Contato:

Arlete Maria Monte de Camargo

Instituto de Ciências da Educação.

Rua Augusto Corrêa, 01, Campus Universitário

do Guamá, Setor Profissional Guamá

Belém |PA |Brasil

CEP 66.075-110

Endereço pessoal:

Travessa Enéas Pinheiro no 2328, Torre Sul apartamento 2304, Bairro Marco

Belém | PA |Brasil

CEP 66.095-015 